\title{
Correction to: A Forecasting Method of Electricity Sales Considering the User Churn Rate in a Power Market Environment
}

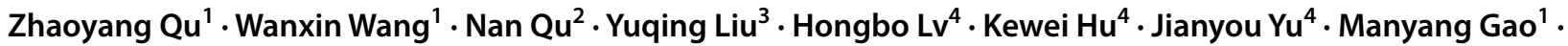 \\ Jiajun Song ${ }^{1}$
}

Published online: 28 August 2019

(c) The Korean Institute of Electrical Engineers 2019

\section{Correction to: \\ Journal of Electrical Engineering \& Technology (2019) 14:1585-1596 \\ https://doi.org/10.1007/s42835-019-00215-9}

Due to unfortunate mistake the grant numbers have been omitted in the acknowledgments section:

This work is supported by the National Natural Science Foundation of China (No. 51437003), Jilin Province Science and Technology Development Plan Project of China (20160623004TC, 20180201092GX), Jilin Science and Technology Innovation Development Plan Project of China (201830817).

Publisher's Note Springer Nature remains neutral with regard to jurisdictional claims in published maps and institutional affiliations.

The original article can be found online at https://doi.org/10.1007/ s42835-019-00215-9.

Wanxin Wang

1269394326@qq.com

Zhaoyang Qu

824937289@qq.com

Nan Qu

1406989666@qq.com

Yuqing Liu

1273225109@qq.com

Hongbo Lv

345654217@qq.com

1 School of Computing Science of Northeast Electric Power University, Jilin, China

2 Maintenaue Company of Jiangsu Power Company, Nanjing, China

3 Department of Electrical and Electronic Engineering of University of Bath, Bath, UK

4 State Grid Jilin Electric Power Supply Company, Jilin, China 